\title{
Black-white racial disparities in sepsis: a prospective analysis of the REasons for Geographic And Racial Differences in Stroke (REGARDS) cohort
}

\author{
Justin Xavier Moore ${ }^{1,2}$, John P. Donnelly ${ }^{1,2,3}$, Russell Griffin², Monika M. Safford ${ }^{3}$, George Howard5,
} John Baddley ${ }^{4}$ and Henry E. Wang ${ }^{1 *}$

\begin{abstract}
Introduction: Sepsis is a major public health problem. Prior studies using hospital-based data describe higher rates of sepsis among black than whites participants. We sought to characterize racial differences in incident sepsis in a large cohort of adult community-dwelling adults.

Methods: We analyzed data on 29,690 participants from the Reasons for Geographic and Racial Differences in Stroke (REGARDS) cohort. We determined the associations between race and first-infection and first-sepsis events, adjusted for participant sociodemographics, health behaviors, chronic medical conditions and biomarkers. We also determined the association between race and first-sepsis events limited to first-infection events. We contrasted participant characteristics and hospital course between black and white sepsis hospitalizations.
\end{abstract}

Results: Among eligible REGARDS participants there were 12,216 (41.1 \%) black and 17,474 (58.9\%) white participants. There were 2,600 first-infection events; the incidence of first-infection events was lower for black participants than for white participants (12.10 vs. 15.76 per 1,000 person-years; adjusted HR 0.65; 95 \% Cl, 0.59-0.71). There were 1,526 first-sepsis events; the incidence of first-sepsis events was lower for black participants than for white participants (6.93 vs. 9.10 per 1,000 person-years, adjusted HR 0.64; $95 \%$ Cl, 0.57-0.72). When limited to first-infection events, the odds of sepsis were similar between black and white participants (adjusted OR 1.01; $95 \% \mathrm{Cl}, 0.84-1.21$ ). Among first-sepsis events, black participants were more likely to be diagnosed with severe sepsis (76.9 \% vs. $71.5 \%)$.

Conclusion: In the REGARDS cohort, black participants were less likely than white participants to experience infection and sepsis events. Further efforts should focus on elucidating the underlying reasons for these observations, which are in contrast to existing literature.

\section{Introduction}

Sepsis is a clinical disease characterized by a systemic inflammatory response to a severe infection. Sepsis is an important public health problem, responsible for more than 750,000 hospitalizations, 570,000 Emergency Department visits and 215,000 deaths annually [1]. In the United States health system, sepsis care exceeds $\$ 16.7$ billion annually [1].

\footnotetext{
* Correspondence: hwang@uabmc.edu

'Department of Emergency Medicine, University of Alabama School of Medicine, 619 19th Street South, OHB 251, Birmingham, AL 35249, USA Full list of author information is available at the end of the article
}

Sepsis survivors are at increased risk of long-term death, cognitive impairment and functional limitation [1-9].

Population-based studies have shown that black individuals have higher rates of sepsis, hospitalization mortality, and are twice more likely to develop sepsis than white individuals [3-6, 10-13]. Over a 22-year study period black participants had higher rates of sepsis than white participants [5]. Mayr et al. found that higher incidence of sepsis among black patients was attributed to higher infectionrelated hospitalization rates and a higher risk of acute organ dysfunction [6]. Barnato, et al. found that even 
while adjusting for poverty, black patients still experienced a higher population-based incidence of severe sepsis [3]. An important feature of these studies was their use of hospital discharge data for identifying sepsis events without information on initial clinical presentation or comorbid conditions. Furthermore, these studies did not distinguish hospital-acquired from community-acquired sepsis events, nor compare hospitalized sepsis patients with non-hospitalized individuals.

The REasons for Geographic and Racial Differences in Stroke (REGARDS) cohort is one of the largest longitudinal cohorts of community-dwelling adults in the United States [14]. The objective of this study was to characterize racial differences in sepsis incidence in the REGARDS cohort.

\section{Methods}

\section{Ethics and consent statement}

The Institutional Review Board of the University of Alabama at Birmingham approved this study. We obtained informed consent from all participants of the study during baseline visit, and we also obtained consent for subsequent blood samples.

\section{Study design and data source}

We performed a prospective cohort analysis using REGARDS, one of the largest ongoing national longitudinal cohorts of community-dwelling adults in the United States [14]. Designed to evaluate geographic and black-white differences in risk factors for stroke, REGARDS recruited 30,239 black and white participants aged $\geq 45$ years. The cohort is $45 \%$ male and 41 \% African American, and $69 \%$ of participants are $>60$ years old. REGARDS recruited participants between January 2003 and October 2007. In 6-month intervals, REGARDS contacted the participants by telephone to identify any hospitalizations experienced by the participant. REGARDS personnel retrieved medical records for specific health events. REGARDS reviewed death certificates, medical records, and interviewed proxies to discern whether a participant died and the causes of the death. Further details of REGARDS study methods are described elsewhere [14].

While the objective of REGARDS was to identify and characterize stroke events, the population of REGARDS included community-dwelling adults at healthy baseline not just individuals who had suffered a prior stroke. The REGARDS-sepsis ancillary study used the infrastructure of the parent REGARDS study to independently identify sepsis hospitalizations.

\section{Identification of serious infection and sepsis events}

We included all hospitalization events reported over a 10year follow-up period ending December 31, 2012. The primary outcomes of this study were 1) first hospitalization for a serious infection, and 2) hospitalization for sepsis. Using the taxonomy of Angus et al., we identified all hospitalizations (Emergency Department visits and/or hospital admission) attributed by participants to a serious infection [1]. Two trained reviewers evaluated information from the corresponding medical record, confirming the presence of a serious infection based upon diagnoses documented in the Emergency Department or admission physician record. Discordances were adjudicated among abstractors, with additional physician review as needed.

Using international consensus definitions, we defined sepsis events as hospital admission for a serious infection with the presence of at least two systemic inflammatory response syndrome (SIRS) criteria, including heart rate $>90$ beats/ minute, fever (temperature $>38.3{ }^{\circ} \mathrm{C}$ or $<36{ }^{\circ} \mathrm{C}$ ), tachypnea ( $>20$ breaths/minute) or PCO $2<32 \mathrm{mmHg}$, and leukocytosis (white blood cells $>12,000$ or $<4,000$ cells $/ \mathrm{mm} 3$ or $>10 \%$ band forms) [1]. We used vital signs and laboratory test results for the initial 28 hours of hospitalization. Because of our focus on communityacquired (vs. hospital-acquired) sepsis, we did not include sepsis developing at later points during hospitalization. We did not include organ dysfunction in the definition of sepsis. Initial review of 1,349 hospital records indicated excellent inter-rater agreement for presence of serious infection (kappa $=0.92$ ) and the presence of sepsis $($ kappa $=0.90)$ upon hospital presentation.

\section{Participant characteristics}

Participant demographics included self-reported age, race, sex, income, education, and geographic location. Health behaviors included tobacco and alcohol use. Smoking status included current, past and never. We defined alcohol use as moderate (one drink per day for women or two drinks per day for men) and heavy alcohol use ( $>1$ drink per day for women and $>2$ drinks per day for men), per the National Institute on Alcohol Abuse and Alcoholism classification [15].

Baseline medical conditions included atrial fibrillation, chronic lung disease, coronary artery disease, deep vein thrombosis, diabetes, dyslipidemia, hypertension, myocardial infarction, obesity, peripheral artery disease, and stroke. We defined atrial fibrillation by participant self-report or baseline electrocardiogram (ECG) evidence of an atrial fibrillation event. Chronic lung disease was defined as participants with a history of prescribed pulmonary medication. Coronary artery disease was classified in participants with a history of heart disease (self-reported myocardial infarction (MI), coronary artery bypass graft, bypass, angioplasty, or stent) or ECG evidence. Diabetes was defined as a fasting glucose level $\geq 126 \mathrm{mg} / \mathrm{L}$ (or a glucose level $\geq 200 \mathrm{mg} / \mathrm{L}$ for those not fasting) or the use of insulin or oral hypoglycemic agents. Dyslipidemia consisted of low-density lipoprotein cholesterol $>130 \mathrm{mg} / \mathrm{dL}$, or use of lipid-lowering medications. Hypertension included systolic blood pressure $\geq 140 \mathrm{~mm} \mathrm{Hg}$, diastolic 


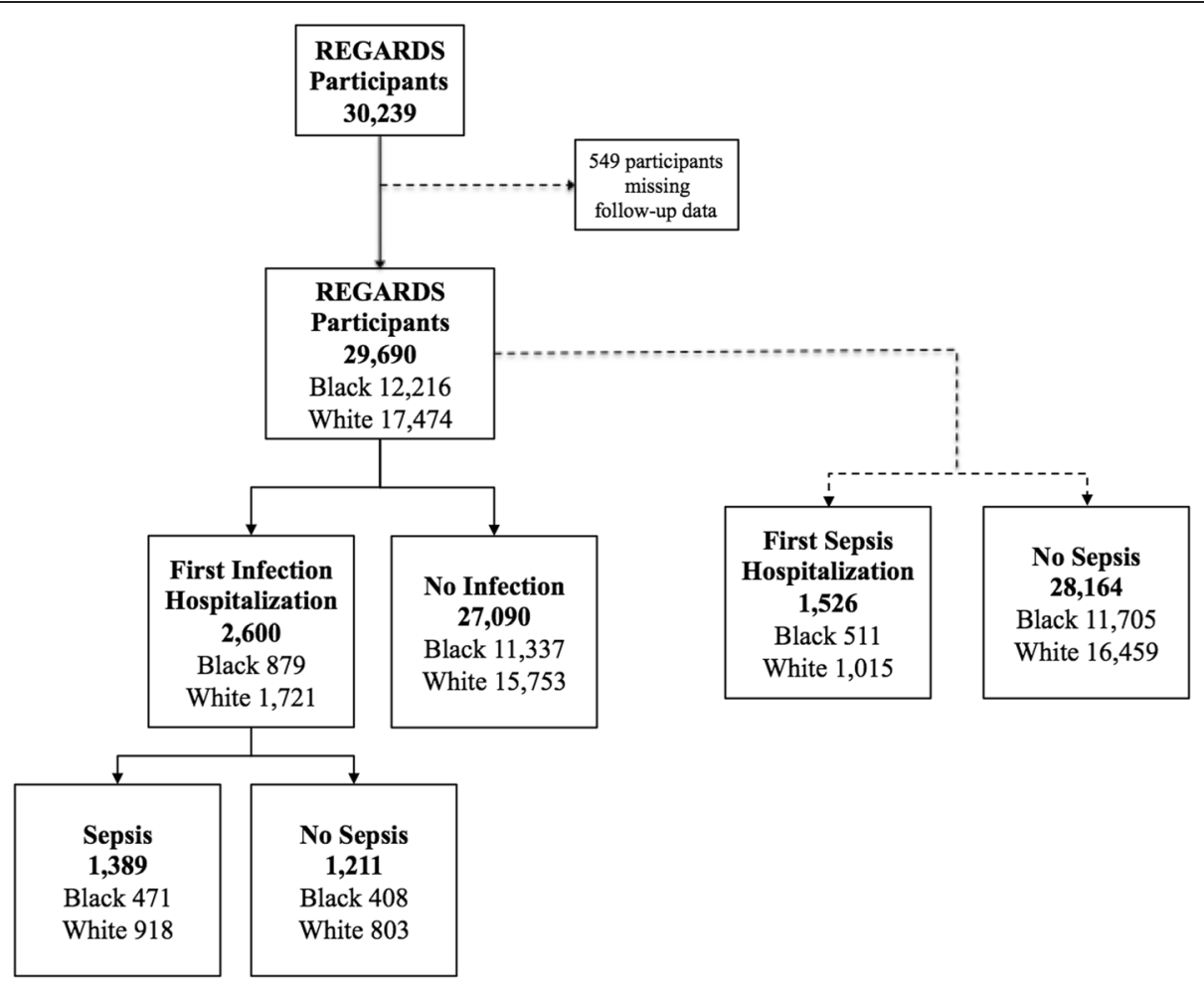

Fig. 1 Flowchart of participants in the Reasons for geographic and racial differences in stroke (REGARDS) study who were included in the analysis

blood pressure $\geq 90 \mathrm{~mm} \mathrm{Hg}$, or the reported use of antihypertensive agents. MI in participants was defined by ECG evidence or self-reports of MI in the participant's history. Obesity was defined as body mass index (BMI) $\geq 30 \mathrm{~kg} / \mathrm{m}^{2}$ in addition to gender-specific waist circumference [16].

REGARDS did not collect information on pulmonary conditions such as asthma and chronic obstructive pulmonary disease. Therefore, we defined participant use of pulmonary medications as a proxy for chronic lung disease. Obtained from each participant's medication inventory, pulmonary medications included beta-2 adrenergic agonists, leukotriene inhibitors, inhaled corticosteroids, combination inhalers, and other pulmonary medications such as ipratropium, cromolyn, aminophylline and theophylline. Other medical conditions such as; deep vein thrombosis, peripheral artery disease, and stroke were based upon self-reports.

\section{Determination of biomarkers}

Biomarkers examined in this study included serum highsensitivity C-reactive protein (hsCRP), urinary albuminto-creatinine ratio (ACR), Cystatin $\mathrm{C}$ (Cyst-C), and estimated glomerular filtration rate (eGFR). We estimated glomerular filtration (eGFR) rate using the Chronic Kidney Disease Epidemiology collaboration (CKD-EPI) equation [17]. We dichotomized all biomarkers as abnormal or normal within statistical models. We defined eGFR $<60 \mathrm{ml} / \mathrm{min} / 1.73 \mathrm{~m}^{2}$ as abnormal. Consistent with our prior study, we defined hsCRP $>3.0 \mathrm{mg} / \mathrm{dL}$ as abnormal [18]. We defined Cyst-C measurements above the fourth quartile of values observed in the REGARDS cohort $(\geq 1.1 \mathrm{mg} / \mathrm{dL})$ as abnormal. We defined ACR $\geq 30 \mathrm{mg} / \mathrm{g}$ as abnormal. Further details of REGARDS biomarkers are defined elsewhere [18-20].

\section{Hospital course}

We defined hospital course as information about selected events during the hospital stay. Hospital course variables included infection type, presence of severe sepsis, sequential organ failure assessment (SOFA) for respiratory, renal hepatic, cardiovascular, hematologic, and neurologic systems, mortality in emergency department sepsis (MEDS) score, ICU admission, hospital mortality, and long-term mortality. We defined severe sepsis as the presence of sepsis and organ dysfunction.

\section{Analysis}

We compared racial differences in baseline demographics and hospital presentation characteristics using the Chi-square test for categorical characteristics, analysis of variance (ANOVA) for continuous characteristics (i.e., age), and the Kruskal-Wallis test for non-parametric continuous variables (i.e., biomarker levels). To estimate the relative rates of first infection and first sepsis in black and white participants, we fit a series of Cox proportional hazards models with time to first infection and time 
Table 1 Baseline characteristics of participants in the Reasons for geographic and racial differences in stroke (REGARDS) study, stratified by race

\begin{tabular}{|c|c|c|c|}
\hline & $\begin{array}{l}\text { Black } \\
(\mathrm{n}=12,216)\end{array}$ & $\begin{array}{l}\text { White } \\
(\mathrm{n}=17,474)\end{array}$ & $P$ value $^{*}$ \\
\hline $\mathrm{Age}^{+}$ & $64.2(9.3)$ & $65.6(9.5)$ & $<0.001$ \\
\hline \multicolumn{4}{|l|}{ Education (\%) } \\
\hline$\leq$ High school & $2,429(19.9)$ & $1,279(7.3)$ & \multirow[t]{4}{*}{$<0.001$} \\
\hline High school graduate & $3,401(27.9)$ & $4,266(24.4)$ & \\
\hline Some college & $3,237(26.5)$ & $4,713(27.0)$ & \\
\hline College grad or more & $3,135(25.7)$ & $7,207(41.3)$ & \\
\hline \multicolumn{4}{|l|}{ Income (\%) } \\
\hline$\leq \$ 20000$ & $3,257(26.7)$ & 2,086 (11.9) & \multirow[t]{5}{*}{$<0.001$} \\
\hline$\$ 20000-\$ 34000$ & $3,223(26.4)$ & $3,951(22.6)$ & \\
\hline$\$ 35000-\$ 74000$ & $3,100(25.4)$ & $5,708(32.7)$ & \\
\hline$\$ 75000$ and Above & 1,088 (8.9) & $3,609(20.7)$ & \\
\hline Refuse & $1,548(12.7)$ & $2,120(12.1)$ & \\
\hline \multicolumn{4}{|l|}{ Geographic region (\%) } \\
\hline Stroke belt ${ }^{a}$ & $6,261(51.3)$ & $10,239(58.6)$ & \multirow[t]{2}{*}{$<0.001$} \\
\hline Non-belt ${ }^{\mathrm{b}}$ & $5,955(48.8)$ & $7,235(41.4)$ & \\
\hline \multicolumn{4}{|l|}{ Sex } \\
\hline Male & $4,622(37.8)$ & $8,713(49.9)$ & \multirow[t]{2}{*}{$<0.001$} \\
\hline Female & $7,594(62.2)$ & $8,761(50.1)$ & \\
\hline \multicolumn{4}{|l|}{ Tobacco use } \\
\hline Never & $5,521(45.4)$ & $7,861(45.1)$ & \multirow[t]{3}{*}{$<0.001$} \\
\hline Past & $4,529(37.3)$ & $7,381(42.4)$ & \\
\hline Current & $2,107(17.3)$ & $2,177(12.5)$ & \\
\hline \multicolumn{4}{|l|}{ Alcohol Use } \\
\hline None & $8,610(72.4)$ & $9,632(55.9)$ & \multirow[t]{3}{*}{$<0.001$} \\
\hline Moderate & $3,002(25.2)$ & $6,689(38.9)$ & \\
\hline Heavy & $288(2.4)$ & $889(5.2)$ & \\
\hline \multicolumn{4}{|l|}{ Baseline medical condition } \\
\hline Atrial fibrillation & $921(7.8)$ & $1,628(9.5)$ & $<0.001$ \\
\hline Chronic lung disease & $960(7.9)$ & $1,771(10.1)$ & $<0.001$ \\
\hline Coronary artery disease & $1,857(15.5)$ & 3,375 (19.6) & $<0.001$ \\
\hline Deep vein thrombosis & $600(4.9)$ & $955(5.5)$ & 0.02 \\
\hline Diabetes & $3,767(31.0)$ & $2,936(16.9)$ & $<0.001$ \\
\hline Dyslipidemia & $6,435(55.3)$ & $10,526(62.1)$ & $<0.001$ \\
\hline Hypertension & $8,706(71.4)$ & $8,840(50.7)$ & $<0.001$ \\
\hline Myocardial infarction & $1,396(11.7)$ & $2,323(13.5)$ & $<0.001$ \\
\hline Obesity & $7,684(63.0)$ & $8,181(46.9)$ & $<0.001$ \\
\hline Peripheral artery disease & $293(2.4)$ & $370(2.1)$ & 0.1 \\
\hline Stroke & $982(8.1)$ & $914(5.3)$ & $<0.001$ \\
\hline \multicolumn{4}{|l|}{ Abnormal biomarker levels ${ }^{€ \#}$} \\
\hline C-reactive protein (CRP) & $2.9(1.2-6.5)$ & $1.9(0.94 .3)$ & $<0.001$ \\
\hline
\end{tabular}


Table 1 Baseline characteristics of participants in the Reasons for geographic and racial differences in stroke (REGARDS) study, stratified by race (Continued)

\begin{tabular}{lll}
\hline Albumin creatinine ratio (ACR) & $8.1(4.7-20.9)$ & $7.2(4.7-14.4)$ \\
Cystatin C & $0.9(0.8-1.1)$ & $1.0(0.8-1.1)$ \\
Estimated glomerular filtration rate (eGFR) & $91.5(73.9-106.8)$ & $85.5(72.2-95.0)$ \\
\hline
\end{tabular}

${ }^{\dagger}$ Mean (standard deviation). ${ }^{a}$ Defined as the states of Alabama, Arkansas, Georgia, Louisiana, Mississippi, North Carolina, South Carolina, and Tennessee;

${ }^{b}$ defined as all other states. *Significance determined using Chi-square test, analysis of variance, or the Kruskal-Wallis test. ${ }^{\epsilon} \mathrm{Median}$ (IQR). ${ }^{\sharp} \mathrm{CRP}$ in mg/dL; eGFR in $\mathrm{ml} / \mathrm{min} / 1.73 \mathrm{~m}^{2} ; A C R$ in $\mathrm{mg} / \mathrm{g} ;$ Cystatin $C$ in $\mathrm{mg} / \mathrm{dL}$

to first sepsis as endpoints. We censored individuals at the time of their event, death, or end of follow up (31 December 2012). We adjusted the estimates for participant sociodemographic data, health behaviors, chronic medical conditions and biomarkers. In a separate sensitivity analysis, we used the Fine and Gray model to examine all-cause mortality among all participants as a potential competing risk for sepsis events [21].

To determine the odds of sepsis among those experiencing an infection, we fit a multivariable logistic regression model assessing the association between sepsis and race, limiting the analysis to those with serious infection. We adjusted the model for sociodemographic data, health behaviors, chronic medical conditions, and biomarkers.

Due to the number of missing values for several variables (income $12.4 \%$, Cyst-C $6.8 \%$, CRP $6.4 \%$, albumin $4.7 \%$, creatinine $4.5 \%$ ), we performed the multivariable modeling with multiple imputation using chained equations (Stata MI suite), pooling regression coefficient estimates for each model across $10 \mathrm{impu-}$ tations using Rubin's rules [22, 23]. We used SAS version 9.4 and Stata version 13 for all analyses. We considered $p$ values $\leq 0.05$ statistically significant.

\section{Results}

\section{Baseline characteristics}

Among 30,239 available participants, 549 participants were excluded from analysis due to incomplete follow-up time, corresponding to 29,690 participants (Fig. 1). Among the 29,690 participants included in this analysis, there were 12,216 (41.1 \%) black participants and 17,474 (58.9\%) white participants (Table 1). Black and white participants had a similar distribution of age, but black participants were more likely to be female than white participants. Black participants reported lower education and income. Tobacco use was similar between races, but black participants were less likely than white participants to use alcohol. Black participants were more likely to have a history of diabetes, hypertension, obesity and stroke. White participants were more likely to have a history of alcohol use, atrial fibrillation, chronic lung disease, coronary artery disease, dyslipidemia, and myocardial infarction.

\section{Rates of serious infection and sepsis}

There were 2,600 first-infection events over the observation period. The incidence of first-infection events was lower for black participants than those who were white

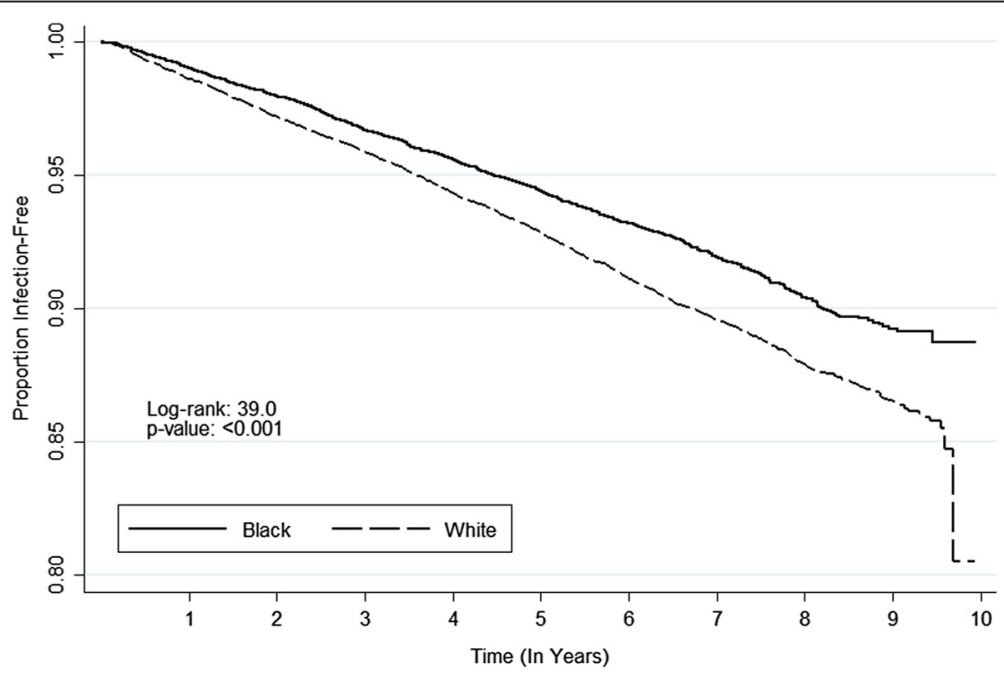

Fig. 2 Kaplan-Meier plot for time to first-infection event, stratified by race 
Table 2 Association between race and first-infection and first-sepsis events

\begin{tabular}{|c|c|c|c|c|c|c|c|}
\hline & \multicolumn{7}{|l|}{ Black vs. white } \\
\hline & \multirow[t]{2}{*}{ Events, number (\%) } & $\begin{array}{l}\text { Incidence density per } \\
1,000 \text { person-years }\end{array}$ & $\begin{array}{l}\text { Crude hazard } \\
\text { ratio* }\end{array}$ & Model $1^{\mathrm{a}}$ & Model $2^{\mathrm{b}}$ & Model $3^{c}$ & Model $4^{d}$ \\
\hline & & $(95 \% \mathrm{Cl})$ & $(95 \% \mathrm{Cl})$ & $(95 \% \mathrm{Cl})$ & $(95 \% \mathrm{Cl})$ & $(95 \% \mathrm{Cl})$ & $(95 \% \mathrm{Cl})$ \\
\hline \multicolumn{8}{|c|}{$\begin{array}{l}\text { First-infection } \\
\text { event }\end{array}$} \\
\hline White & $1721(5.8)$ & $15.76(15.65,15.87)$ & $0.77(0.71,0.84)$ & $0.70(0.64,0.76)$ & $0.68(0.63,0.75)$ & $0.65(0.59,0.71)$ & $0.65(0.59,0.71)$ \\
\hline Black & $879(3.0)$ & $12.10(11.95,12.26)$ & & & & & \\
\hline \multicolumn{8}{|c|}{ First-sepsis event } \\
\hline White & $1015(3.4)$ & $9.10(8.96,9.25)$ & $0.76(0.69,0.85)$ & $0.68(0.61,0.76)$ & $0.67(0.60,0.75)$ & $0.63(0.56,0.71)$ & $0.64(0.57,0.72)$ \\
\hline \multirow[t]{3}{*}{ Black } & $511(1.7)$ & $6.93(6.73,7.13)$ & & & & & \\
\hline & Events, number (\%) & - & Crude odds ratio $\neq$ & Model $1^{\mathrm{a}}$ & Model $2^{b}$ & Model $3^{c}$ & Model $4^{d}$ \\
\hline & & & $(95 \% \mathrm{Cl})$ & $(95 \% \mathrm{Cl})$ & $(95 \% \mathrm{Cl})$ & $(95 \% \mathrm{Cl})$ & $(95 \% \mathrm{Cl})$ \\
\hline \multicolumn{8}{|c|}{ Sepsis (given first-infection event) } \\
\hline White & $918(53.4)$ & - & $1.01(0.86,1.19)$ & $0.99(0.84,1.18)$ & $0.99(0.83,1.17)$ & $1.00(0.83,1.19)$ & $1.01(0.84,1.21)$ \\
\hline Black & $471(53.5)$ & - & & & & & \\
\hline
\end{tabular}

${ }^{\mathrm{a} A d j u s t e d}$ for sex, age, and geographic region, education level, and income. ${ }^{\mathrm{b}}$ Adjusted for model 1 covariates plus tobacco and alcohol use. ${ }^{\mathrm{c}}$ Adjusted for model 2 covariates plus baseline chronic medical conditions. ${ }^{\mathrm{d}}$ Adjusted for model 3 covariates plus biomarkers. *Estimated from Cox proportional hazard model.

${ }^{\ddagger}$ Estimated from logistic regression

(12.10 vs. 15.76 per 1,000 person-years, hazard ratio (HR) $0.77 ; 95 \%$ CI, 0.71, 0.84) (Fig. 2, Table 2). The observed reduced hazard of first infection among black participants was more pronounced after adjustment for demographic data, health behaviors, chronic medical conditions, and biomarkers (adjusted HR 0.65; 95 \% CI, 0.59, 0.71) (Fig. 2, Table 2).

Among study participants there were 1,526 first-sepsis events over the observation period. The incidence of firstsepsis events was lower for black participants than white participants (6.93 vs. 9.10 per 1,000 person-years, HR 0.76; $95 \%$ CI, 0.69, 0.85) (Fig. 3, Table 2). Similar to results for infection, the association was more pronounced after adjustment for demographics, health behaviors, chronic medical conditions, and biomarkers (adjusted HR 0.64; 95 \% CI, 0.57, 0.72) (Fig. 3, Table 2).

Among the 2,600 first-infection events, 1,389 fulfilled sepsis criteria. Limited to the first-infection participants, the odds ratio (OR) for sepsis was similar between races (OR 1.01; $95 \%$ CI, 0.86, 1.19). This association did not change after adjustment for confounders (adjusted OR 1.01; 95 \% CI, 0.84, 1.21).

\section{Hospital presentation and course}

Within the 2,600 first-infection events, infection types, severe sepsis frequency, SOFA scores, MEDS scores,

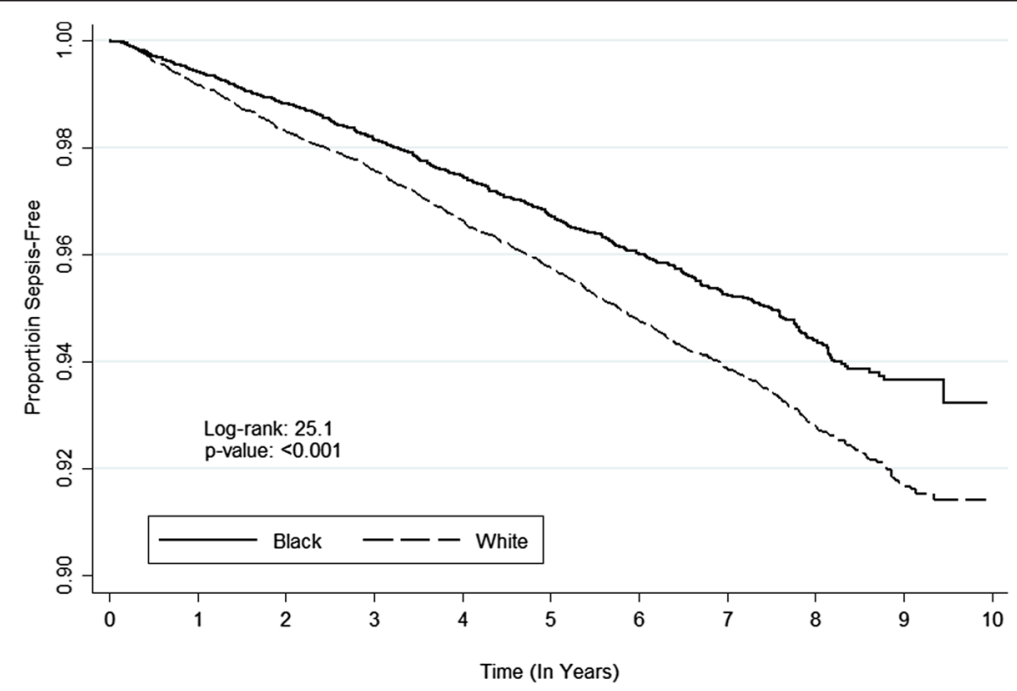

Fig. 3 Kaplan-Meier plot for time to first sepsis, stratified by race 
Table 3 Hospital presentation and course for first-infection events stratified by race

\begin{tabular}{|c|c|c|c|}
\hline & $\begin{array}{l}\text { Black } \\
(\mathrm{n}=879)\end{array}$ & $\begin{array}{l}\text { White } \\
(\mathrm{n}=1,721)\end{array}$ & $P$ value ${ }^{*}$ \\
\hline Infection type (\%) & & & 0.06 \\
\hline Lung & $364(41.4)$ & $705(41.0)$ & \\
\hline Kidney & $168(19.1)$ & $311(18.1)$ & \\
\hline Abdominal & $132(15.0)$ & $338(19.7)$ & \\
\hline Skin & $117(13.3)$ & $214(12.4)$ & \\
\hline Sepsis & $44(5.0)$ & $71(4.1)$ & \\
\hline Other & $54(6.1)$ & $82(4.8)$ & \\
\hline Severe sepsis (\%) & $360(41.0)$ & $662(38.5)$ & 0.2 \\
\hline SOFA score s* $^{* *}$ & $2(1-4)$ & $2(1-3)$ & 0.06 \\
\hline MEDS score $e^{* * *}$ & $3(3-6)$ & $3(3-9)$ & 0.2 \\
\hline Admission to ICU (\%) & $65(7.4)$ & $133(7.7)$ & 0.8 \\
\hline Hospital mortality (\%) & $59(6.7)$ & $104(6.0)$ & 0.5 \\
\hline Long-term mortality (\%) & $227(25.8)$ & $404(23.4)$ & 0.2 \\
\hline
\end{tabular}

*Estimated using either the Chi-square or Wilcoxon test. **Sequential organ failure assessment (SOFA) score, 28 hours, median (IQR). ${ }^{* *}$ Mortality in Emergency Department sepsis (MEDS) score, median (IQR)

ICU admission, hospital mortality, and long-term mortality were similar in black and white participants (Table 3). Among 1,526 first-sepsis events, black participants had higher proportions of severe sepsis and slightly higher SOFA scores (Table 4). Infection types, MEDS scores, ICU admission, hospital mortality and long-term mortality were similar in black and white participants.

Table 4 Hospital presentation and course for first-sepsis events stratified by race

\begin{tabular}{llll}
\hline & $\begin{array}{l}\text { Black } \\
(\mathrm{n}=511)\end{array}$ & $\begin{array}{l}\text { White } \\
(\mathrm{n}=1,015)\end{array}$ & $P$ value $^{*}$ \\
\hline $\begin{array}{l}\text { Infection type (\%) } \\
\text { Lung }\end{array}$ & $235(46.0)$ & $503(49.5)$ & 0.04 \\
Kidney & $93(18.2)$ & $167(16.4)$ & \\
Abdominal & $66(12.9)$ & $166(16.3)$ & \\
$\quad$ Skin & $47(9.2)$ & $76(7.5)$ & \\
$\quad$ Sepsis & $42(8.2)$ & $61(6.0)$ & \\
$\quad$ Other & $28(5.5)$ & $44(4.3)$ & \\
Severe sepsis (\%) & $393(76.9)$ & $726(71.5)$ & 0.02 \\
SOFA score* & $2(1-4)$ & $2(1-3)$ & 0.04 \\
MEDS score*** & $3(3-6)$ & $3(3-9)$ & 0.2 \\
Admission to ICU (\%) & $63(12.3)$ & $125(12.3)$ & 1.0 \\
Hospital mortality (\%) & $53(10.4)$ & $87(8.6)$ & 0.3 \\
Long-term mortality (\%) & $162(31.7)$ & $296(29.2)$ & 0.3 \\
\hline
\end{tabular}

*Estimated using either the Chi-square or Wilcoxon test. **Sequential organ failure assessment (SOFA) score, 28 hours, median (IQR). ***Mortality in Emergency Department sepsis (MEDS) score, median (IQR)

\section{Sensitivity analysis}

When accounting for all-cause mortality as a competing risk, the increased rates of sepsis among white participants persisted (adjusted sub-HR 0.66; $95 \%$ CI, 0.57, 0.75) (Fig. 4).

\section{Discussion}

Prior epidemiological studies using hospital discharge data have reported higher incidence of sepsis and severe sepsis among black patients compared to those who were white (Table 5) [3-6, 10-13]. However, in this population-based study of community-dwelling adults in the REGARDS cohort, we found that black participants were at lower risk of developing sepsis than white participants. This contrasting racial disparity appeared to be due to lower rates of hospitalization for a serious infection. Once hospitalized for a serious infection, the odds of sepsis were similar in black and white participants. Among those hospitalized for sepsis, black participants were slightly more likely have severe sepsis, but other aspects of the hospital course were similar between races.

The differences in observed race-sepsis associations between the current and prior studies could be explained by differences in the identification of sepsis events. Previous studies have applied ICD-9 taxonomies of Martin, et al. and Angus, et al. in order to identify sepsis and severe sepsis hospitalizations (Table 5) [3-6, 10-13]. This approach could lead to documentation bias, and research suggests that the use of discharge diagnoses tends to have poor sensitivity to detect sepsis $[24,26]$. For example, a recent study concluded that ICD-9 discharge diagnoses were highly specific $(94.6 \%)$ but had poor sensitivity $(27.6 \%)$ for detecting community-acquired sepsis events. [26]. Due to the fact that present-on-admission flags are not commonly available in discharge datasets used for research purposes, prior sepsis studies were also unable to disentangle early community-acquired sepsis from later hospital-acquired sepsis. Moreover, documentation bias is plausible if physicians were more likely to record sepsis, infection and organ dysfunction diagnoses based on the patient's race.

In contrast to prior work, our study employed comprehensive chart review in the definition of sepsis events. By using a definition that encompassed laboratory measurements and documentation of an infection, it is plausible that differences in sepsis detection could be attributable to hospital or ED practices. Specifically, patterns of initial diagnostic testing may have varied between black and white participants based on the site of presentation, leading to differing rates of sepsis. This assertion is supported by prior research, which indicates that black patients receive inferior care, such as lower quality and intensity of care [27]. Although we were not 


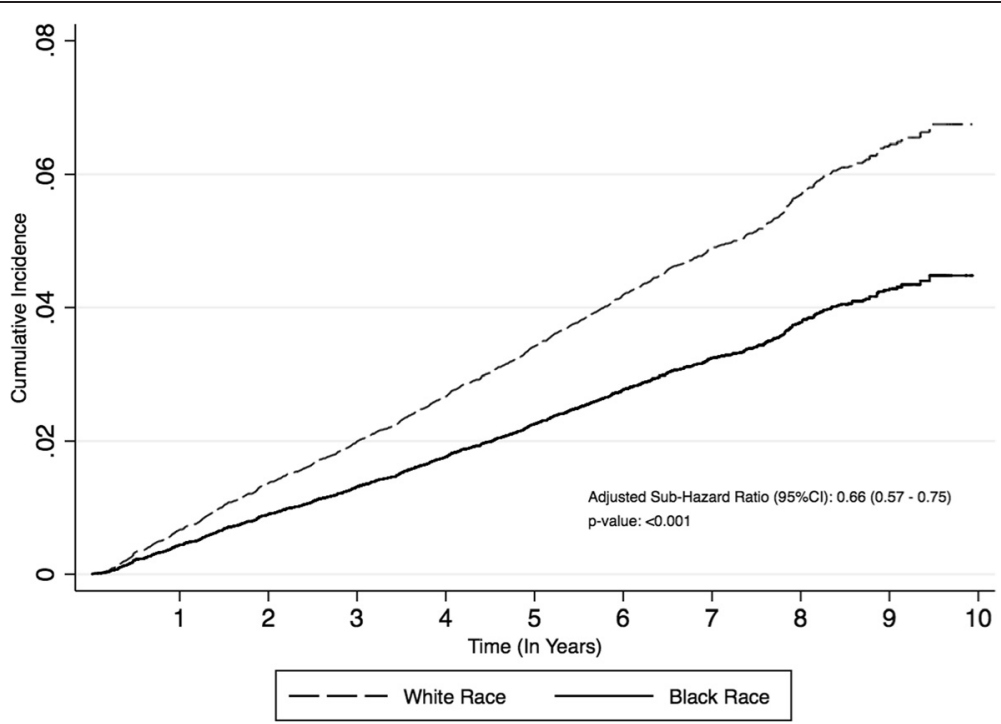

Fig. 4 Competing Risks Analysis: Cumulative incidence function and adjusted sub-hazard ratio, stratified by race

able to explore differences in hospital quality in the current analysis, this is an intriguing area of future research.

Studies performed across a wide range of disciplines indicate that impaired access to care or healthcare status causes delayed hospital presentation among African Americans compared to other races [27-30]. An interesting question is whether white participants may have had better access to quality outpatient infection care than black participants, with only those with more serious illness presenting to the hospital for care. This hypothesis is tempered by the fact that we observed similar SOFA and MEDS scores between races. The contrasting findings between the current and prior studies may have also occurred if black participants were more likely than white participants to develop hospitalacquired sepsis. Mayr, et al. (2010) found that black

Table 5 Association between sepsis and race as determined in eight studies

\begin{tabular}{|c|c|c|c|c|c|c|}
\hline Authors & Data & $\begin{array}{l}\text { Method for sepsis case } \\
\text { identification }\end{array}$ & $\begin{array}{l}\text { Study } \\
\text { Period }\end{array}$ & $\begin{array}{l}\text { Population } \\
\text { age }(\text { mean)* }\end{array}$ & $\begin{array}{l}\text { Primary } \\
\text { outcome }\end{array}$ & $\begin{array}{l}\text { Sepsis rate ratio** } \\
\text { black vs. white }\end{array}$ \\
\hline \multirow[t]{2}{*}{ Baine et al., 2001 [10] } & \multirow[t]{2}{*}{ US Medicare discharge data } & \multirow{2}{*}{$\begin{array}{l}\text { ICD-9-CM discharge } \\
\text { diagnoses }\end{array}$} & \multirow[t]{2}{*}{$1991-1998$} & \multirow[t]{2}{*}{$65-89$ years } & \multirow[t]{2}{*}{ Septicemia } & Black men RR 2.44 \\
\hline & & & & & & Black women RR 2.13 \\
\hline \multirow[t]{2}{*}{ Barnato et al., 2008 [3] } & \multirow{2}{*}{$\begin{array}{l}\text { Six-state hospital discharge } \\
\text { and US Census data }\end{array}$} & \multirow{2}{*}{$\begin{array}{l}\text { ICD-9-CM discharge } \\
\text { diagnoses }\end{array}$} & \multirow[t]{2}{*}{2001} & \multirow[t]{2}{*}{ All ages (36.1) } & \multirow{2}{*}{$\begin{array}{l}\text { Severe } \\
\text { sepsis }\end{array}$} & Black RR 1.44; \\
\hline & & & & & & $95 \% \mathrm{Cl} 1.42,1.46$ \\
\hline Dombrovskiy et al., 2007 [4] & $\begin{array}{l}\text { New Jersey state } \\
\text { discharge data }\end{array}$ & $\begin{array}{l}\text { ICD-9-CM discharge } \\
\text { diagnoses }\end{array}$ & 2002 & $\geq 18$ years & Sepsis & Black RR 2.28 \\
\hline \multirow[t]{2}{*}{ Esper et al., 2006 [11] } & \multirow[t]{2}{*}{$\begin{array}{l}\text { National representative } \\
\text { sample of discharge data }\end{array}$} & \multirow[t]{2}{*}{$\begin{array}{l}\text { ICD-9-CM discharge } \\
\text { diagnoses }\end{array}$} & \multirow[t]{2}{*}{ 1979-2003 } & \multirow[t]{2}{*}{$(60.5)$} & \multirow[t]{2}{*}{ Sepsis } & $\begin{array}{l}\text { Mean annual } \\
\text { black RR 1.90; }\end{array}$ \\
\hline & & & & & & $95 \% \mathrm{Cl} 1.82,1.98$ \\
\hline \multirow[t]{2}{*}{ Martin et al., 2003 [5] } & \multirow[t]{2}{*}{$\begin{array}{l}\text { National representative } \\
\text { sample of discharge data }\end{array}$} & \multirow[t]{2}{*}{$\begin{array}{l}\text { ICD-9-CM discharge } \\
\text { diagnoses }\end{array}$} & \multirow[t]{2}{*}{ 1979-2000 } & \multirow[t]{2}{*}{$(60.8)$} & \multirow[t]{2}{*}{ Sepsis } & $\begin{array}{l}\text { Mean annual } \\
\text { black RR 1.90; }\end{array}$ \\
\hline & & & & & & $95 \% \mathrm{Cl} 1.81,2.00$ \\
\hline Mayr et al., 2010 [6] & $\begin{array}{l}\text { Seven-state hospital } \\
\text { discharge and US } \\
\text { Census data. }\end{array}$ & $\begin{array}{l}\text { ICD-9-CM discharge } \\
\text { diagnoses }\end{array}$ & 2005 & All ages & $\begin{array}{l}\text { Severe } \\
\text { sepsis }\end{array}$ & Black IRR 1.67 \\
\hline McBean et al., 2001 [12] & US Medicare discharge data. & $\begin{array}{l}\text { ICD-9-CM discharge } \\
\text { diagnoses }\end{array}$ & 1986-1997 & $\geq 65$ years & Septicemia & Black RR 1.97 \\
\hline \multirow[t]{2}{*}{ Richardus et al., 2001 [13] } & \multirow{2}{*}{$\begin{array}{l}\text { National Longitudinal } \\
\text { Mortality Study }\end{array}$} & \multirow{2}{*}{$\begin{array}{l}\text { ICD-9-CM discharge } \\
\text { diagnoses }\end{array}$} & \multirow[t]{2}{*}{ 1979-1989 } & \multirow[t]{2}{*}{$\geq 20$ years } & \multirow[t]{2}{*}{ Septicemia } & Black RR 1.87; \\
\hline & & & & & & $95 \% \mathrm{Cl} 1.35,2.58$ \\
\hline
\end{tabular}


participants were more likely to develop postoperative infections than their white counterparts, which would support this hypothesis [6]. Because of our focus on community-acquired sepsis, we did not examine the later parts of the hospital course to identify the development of hospital-acquired sepsis.

Racial disparities are important because they may reflect differences in biological response, genetics, health behaviors, or access to or quality of medical care. Studies of hepatitis $\mathrm{C}$ virus and coronary heart disease have affirmed the presence of racial disparities due to differences in all of these domains [31-33]. In the national effort to reduce sepsis morbidity and mortality, racial differences might shed light on the pathophysiologic or clinical factors that influence sepsis outcomes. Some may view our results as negating the need for scrutinizing racial disparities. On the contrary, our findings - especially as they contrast with prior studies - signal the need to more intensely explore racial differences.

\section{Limitations}

REGARDS is a longitudinal study intended to investigate stroke, and not sepsis outcomes. The current analysis is not a surveillance study, and thus we may not have achieved complete ascertainment of all sepsis events. Recall bias is a limitation, and therefore the number of sepsis events identified may be underestimates. By design, the REGARDS cohort includes only African Americans and white Americans, and thus these results may not be generalizable to other ethnic groups. REGARDS oversampled black participants in the southeastern US, potentially limiting generalizability to other populations.

Selection bias or participation bias are potential limitations of this study. By design, the REGARDS cohort contains individuals over 45 years old only; sepsis rates and the observed associations may have differed for younger individuals. Thus, it is possible that black participants may have experienced more sepsis-related events at younger ages than white participants, an observation made in previous research [4]. Participants may have been less likely to participate in the baseline visit of study based on work status (i.e., black men were less likely to participate). This is largely explained by required blood management visits at baseline during morning weekdays, which may have alternatively required missed workdays. However, this is likely an equal burden for all race-sex strata, but could have been more prevalent for black men. We identified individuals who presented to the hospital with sepsis, but did not include those who acquired sepsis during their hospitalization. Participants in the REGARDS cohort could be significantly different from prior studied populations. However, previous studies investigating the REGARDS cohort have observed racial differences consistent with other cohorts; for example, black participants having higher risk of fatal coronary heart disease than white participants [32].

REGARDS did not have information on vaccination, so we could not ascertain if racial differences in vaccinations may have resulted in different infection rates. Prior research suggests that black patients have a higher incidence of infections (e.g., bacteremic pneumonia) than white patients [34, 35]. Robinson, et al. explained that the racial disparity could be attributed to lower vaccination rates among black patients [35]. Furthermore, an additional study found that after the introduction of the pneumococcal vaccine, the disparity between black and white participants diminished [36].

\section{Conclusion}

In conclusion, in the national REGARDS cohort, black participants were less likely than white participants to experience infection and sepsis events. However, after hospitalization for first infection there were no racial differences in the odds of sepsis. Further efforts should focus on elucidating the underlying reasons for these observations, which are in contrast to existing literature.

\section{Key messages}

- In the REGARDS cohort, the long-term risk of community-acquired sepsis is higher in white participants than in black participants.

- In this study, white participants were more likely to develop both infection and sepsis.

- Among those with first infections, the odds of sepsis were not different between black and white participants.

\section{Abbreviations}

ACR: albumin-to-creatinine ratio; BMI: body mass index; CKD-EPI: Chronic Kidney Disease Epidemiology Collaboration equation; CRP: C-reactive protein; Cyst-C: Cystatin-C; ECG: electrocardiogram; eGFR: estimated glomerular filtration rate; HR: hazard ratio; MEDS: mortality in emergency department; MI: myocardial infarction; OR: odds ratio; REGARDS: Reasons for geographic and racial differences in stroke; SIRS: systemic inflammatory response syndrome; SOFA: sequential organ failure assessment; WC: waist circumference.

\section{Competing interest}

Dr Safford reports the following potential conflicts of interest: Amgen - salary support to study patterns of statin use in Medicare and other large databases; diaDexus - salary support for a research grant on lipids and CHD outcomes; diaDexus - consulting to help with FDA application; $\mathrm{NIH}$, AHRQ - salary support for research grants. Mr Moore, Mr Donnelly and Drs, Griffin, Wang, Howard, and Baddley do not report any related conflicts of interest.

\section{Authors' contributions}

JXM was involved in the conception of the study, participated in the design of the study, performed statistical analysis and interpretation of the data, and drafted the manuscript. JPD participated in the design of the study and participated in the statistical analysis. RG participated in the design of the study and participated in the statistical analysis. MMS was involved in the conception of the study and participated in the design of the study. GH was 
involved in the conception of the study and participated in the design of the study. JB was involved in the conception of the study and participated in the design of the study. HEW was involved in the conception of the study, participated in the design of the study, participated in the statistical analysis and interpretation of the data, and helped to draft the manuscript. All authors revised the manuscript critically for important intellectual content, gave final approval of the version to be published, and take responsibility for the integrity of the data and the accuracy of the data analysis.

\section{Acknowledgements}

This study was supported by award R01-NR012726 from the National Institute for Nursing Research, UL1-RR025777 from the National Center for Research Resources, and by grants from the Center for Clinical and Translational Science and the Lister Hill Center for Health Policy of the University of Alabama at Birmingham. The parent REGARDS study was supported by cooperative agreement U01-NS041588 from the National Institute of Neurological Disorders and Stroke, National Institutes of Health, Department of Health and Human Service. The content is solely the responsibility of the authors and does not necessarily represent the official views of the funding agencies. Representatives of the funding agencies have been involved in the review of the manuscript but not directly involved in the collection, management, analysis or interpretation of the data. The authors thank the other investigators, the staff, and the participants of the REGARDS study for their valuable contributions. A full list of participating REGARDS investigators and institutions can be found at http://www.regardsstudy.org and http://www.regardssepsis.org. Mr Donnelly received support from the Agency for Healthcare Research and Quality, Rockville, Maryland (T32-HS013852).

\section{Author details}

${ }^{1}$ Department of Emergency Medicine, University of Alabama School of Medicine, 619 19th Street South, OHB 251, Birmingham, AL 35249, USA ${ }^{2}$ Department of Epidemiology, University of Alabama at Birmingham, Birmingham, Alabama, USA. ${ }^{3}$ Division of Preventive Medicine, Department of Medicine, University of Alabama School of Medicine, Birmingham, Alabama, USA. ${ }^{4}$ Division of Infectious Diseases, Department of Medicine, University of Alabama School of Medicine, Birmingham, Alabama, USA. ${ }^{5}$ Department of Biostatistics, University of Alabama at Birmingham, Birmingham, Alabama, USA.

\section{Received: 27 March 2015 Accepted: 19 June 2015}

\section{Published online: 10 July 2015}

\section{References}

1. Angus DC, Linde-Zwirble WT, Lidicker J, Clermont G, Carcillo J, Pinsky MR. Epidemiology of severe sepsis in the United States: Analysis of incidence, outcome, and associated costs of care. Crit Care Med. 2001;29:1303-10.

2. Angus DC. The lingering consequences of sepsis: A hidden public health disaster? JAMA. 2010;304:1833-4.

3. Barnato AE, Alexander SL, Linde-Zwirble WT, Angus DC. Racial variation in the incidence, care, and outcomes or severe sepsis: analysis of population, patient, and hospital characteristics. Am J Respir Crit Care Med. 2008;177:279-84

4. Dombrovskiy WY, Martin AA, Sunderram J, Paz HL. Occurrence and outcomes of sepsis: influence of race. Crit Care Med. 2007;35:763-8.

5. Martin GS, Mannino DM, Eaton S, Moss M. The epidemiology of sepsis in the United States from 1979 through 2000. N Engl J Med. 2003;348:1546-54.

6. Mayr FB, Yende S, Linde-Zwirble WT, Peck-Pamler OM, Weissfeld LA, Angus DC. Infection rate and acute organ dysfunction risk as explanations for racial differences in severe sepsis. JAMA. 2010;303:2495-503.

7. Mayr FB, Yende S, Angus DC. Epidemiology of severe sepsis. Virulence. 2014;5:4-11

8. Wang HE, Shapiro NI, Angus DC, Yealy DM. National estimates of severe sepsis in United States emergency departments. Crit Care Med. 2007;35:1928-36.

9. Wang HE, Devereaux RS, Yealy DM, Safford MM, Howard G. National variation in United States sepsis mortality: a descriptive study. Int J Health Geogr. 2010;9:1-9.

10. Baine $W$, Yu W, Summe JP. The epidemiology of hospitalization of elderly Americans for septicemia or bacteremia in 1991-1998. Application of Medicare claims data. Ann Epidemiol. 2001;11:118-26.
11. Esper AM, Moss M, Lewis CA, Nisbet R, Mannino DM, Martin GS. The role of infection and comorbidity: Factors that influence disparities in sepsis. Crit Care Med. 2006;34:2576-82.

12. McBean M, Rajamani S. Increasing rates of hospitalization due to septicemia in the US elderly population, 1986-1997. J Infect Dis. 2001;183:596-603.

13. Richardus $\mathrm{JH}$, Kunst AE. Black-white differences in infectious disease mortality in the United States. Am J Public Health. 2001;91:1251-3.

14. Howard VJ, Cushman M, Pulley L, Gomez CR, Go RC, Prineas RJ, et al. The reasons for geographic and racial differences in stroke study: objectives and design. Neuroepidemiology. 2005;25:135-43.

15. Willenbring ML, Massey SH, Gardner MB. Helping patients who drink too much: an evidence-based guide for primary care clinicians. Am Fam Physician. 2009;80:44-50.

16. Navaranjan D, Rosella LC, Kwong JC, Campitelli M, Crowcroft N. Ethnic disparities in acquiring 2009 pandemic H1N1 influenza: a case-control study. BMC Public Health. 2014;14:214

17. Gotch FA, Kotanko P, Thijssen S, Levin NW. The KDIGO guideline for dialysate calcium will result in an increased incidence of calcium accumulation in hemodialysis patients. Kidney Int. 2010;78:343-50.

18. Wang H, Shapiro N, Safford MM, Griffin R, Judd S, Rodgers JB, et al. High-sensitivity C-reactive protein and risk of sepsis. PLoS One. 2013:8:e69232.

19. Powell TC, Donnelly JP, Gutierrez OM, Griffin RL, Safford MM, Wang HE. Cystatin C and long term risk of community-acquired sepsis: a population-based cohort study. BMC Nephrol. 2015;16:10.

20. Wang HE, Shapiro NI, Griffin R, Safford MM, Judd S, Howard G. Inflammatory and endothelial activation biomarkers and risk of sepsis: a nested case-control study. J Crit Care. 2012;28:549-55.

21. Fine JP, Gray RJ. A proportional hazards model for the subdistribution of a competing risk. J Am Stat Assoc. 1999;94:496-509.

22. Rubin DB, Schenker N. Multiple imputation in health-care databases: an overview and some applications. Stat Med. 1991;10:585-98.

23. Rubin DB. Multiple imputation after 18+ years. J Am Stat Assoc. 1996;91:473-89.

24. Iwashyna TJ, Ely EW, Smith DM, Langa KM. Long-term cognitive impairment and functional disability among survivors of severe sepsis. JAMA. 2010;304:1787-94.

25. Jolley RJ, Sawka KJ, Yergens DW, Quan H, Jette N, Doig CJ. Validity of adminstrative data in recording sepsis: a systematic review. Crit Care. 2015;19:12.

26. Wang HE, Addis DR, Donnelly JP, Shapiro NI, Griffin RL, Safford MM, et al. Discharge diagnoses versus medical record review in the identification of community-acquired sepsis. Crit Care. 2015;19:11.

27. Vogel T. Update and review of racial disparities in sepsis. Surg Infect (Larchmt). 2012;13:203-8.

28. O'Brien JM, Lu B, Ali NA, Levine DA, Aberegg SK, Lemeshow S. Insurance type and sepsis-associated hospitalizations and sepsis-assocated mortality among US adults: A retrospective cohort study. Crit Care. 2011;15:11.

29. Parikh AA, Robinson J, Zaydfudim VM, Penson D, Whiteside MA. The effect of health insurance status on the treatment and outcomes of patients with colorectal cancer. J Surg Oncol. 2014;110:227-32.

30. Oramasionwu CU, Brown CM, Ryan L, Lawson KA, Hunter JM, Frei CR. HIV/AIDS disparities: the mounting epidemic plaguing US Blacks. J Natl Med Assoc. 2009;101:1196-204.

31. Soto GJ, Martin GS, Gong MN. Healthcare disparities in critical illness Crit Care Med. 2013;41:2784-93.

32. Safford MM, Brown TM, Muntner P, Durant RW, Glasser S, Halanych JH, et al. Association of race and sex with risk of incident acute coronary heart disease events. JAMA. 2012;308:1768-74.

33. Liu G, Holmberg SD, Kamili S, Xu F. Racial disparities in the proportion of current, unresolved hepatitis c virus infections in the United States, 2003-2010. Dig Dis Sci. 2014;59:1950-7.

34. Burton DC, Flannery B, Bennett NM, Farley MM, Gershman K, Harrison LH, et al. Socioeconomic and racial/ethnic disparities in the incidence of bacteremic pneumonia among U.S. adults. Res Pract. 2010;100:1904-11.

35. Robinson KA, Baughman W, Rothrock G, Barrett NL, Pass M, Lexau C, et al. Epidemiology of invasive streptococcus pneumoniae infections in the united states, 1995-1998. JAMA. 2001;285:1729-35.

36. Talbot TR, Poehling KA, Hartert TV, Arbogast PG, Halasa NB, Mitchel E, et al. Elimination of racial differences in invasive pneumococcal disease in young children after introduction of the conjugate pneumococcal vaccine. Pediatr Infect Dis J. 2004;23:726-31. 